\title{
TRABAJADOR DEL CONOCIMIENTO Y EL SALTO A LA INNOVACIÓN
}

Maité Darceles Tife*

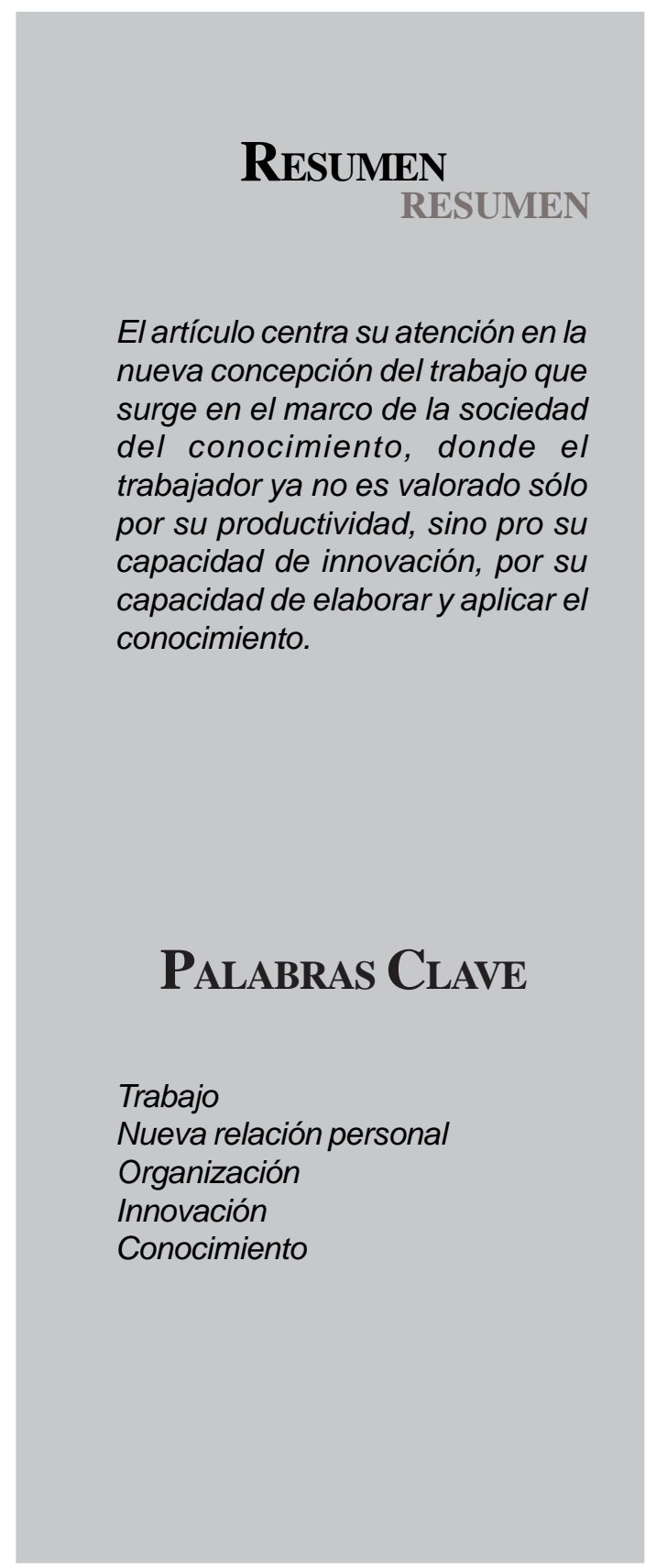
El trabajo y la nueva relación persona - organización

0

e dice que la sociedad ha cambiado más en la última década que en los 20 años anteriores y que el ritmo de transformación va a seguir acelerándose.

Uno de los cambios más profundos se está produciendo en la concepción del trabajo. Será determinante para un progreso real de la sociedad que las personas compartamos metas con nuestras organizaciones, identificándonos más con nuestro trabajo, y que éste contribuya en mayor medida a nuestra autorrealización y desarrollo personales. Habrá que agudizar el ingenio, actuar con habilidad y cooperar mucho para que nos vayamos aproximando hacia una realidad así.

Es avanzar que el trabajo se convierta en un espacio de desarrollo personal. Además, desde una perspectiva bien distinta, este camino de impulsar las potencialidades de las personas y de buscar la identificación entre intereses de persona y organización, es el único hacia el

* Colaboradora del Cluster del Conocimiento. 
progreso económico, al menos en las economías más avanzadas, como intento argumentar a lo largo de estas líneas.

Porter distingue tres estadios de avance económico. En el primero, la economía está impulsada por los factores de producción. En este estadio suelen ser fuente de ventaja competitiva los bajos salarios y los recursos naturales. En el segundo, basado en la inversión, la fuente de ventaja competitiva es la productividad o eficiencia en la producción de bienes y servicios estandarizados. En el tercer estadio, la capacidad de innovar se constituye en fuente de ventaja competitiva. Innovar es crear ideas y conocimiento que per-mitan obtener productos, servicios, procesos y relaciones nuevos o mejorados y aplicarlos a la cadena de valor.

Pasar del segundo al tercer estadio, o competir en el tercero, -que es a lo que debemos aspirarrequiere un cambio total de enfoque con respecto a la idea de trabajo y la relación persona - organización.

En épocas anteriores, sólo se entendía la relación persona - organización desde la confrontación. Aún hoy en la mayoría de los sindicatos y muchos ámbitos empresariales predomina la cultura de la confrontación. A pesar de ello, hoy podemos afirmar que hay muchos intereses convergentes, por lo que podemos ser algo optimistas:

1. Las personas esperan más que una remuneración adecuada de su trabajo: esperan aportar y ser reconocidas.

2. La organización necesita que el trabajador del conocimiento se comprometa. Como dice Drucker el trabajador del conocimiento es el único factor de producción que permite a las sociedades y economías altamente desarrolladas competir entre sí (Drucker, 2003: 88).

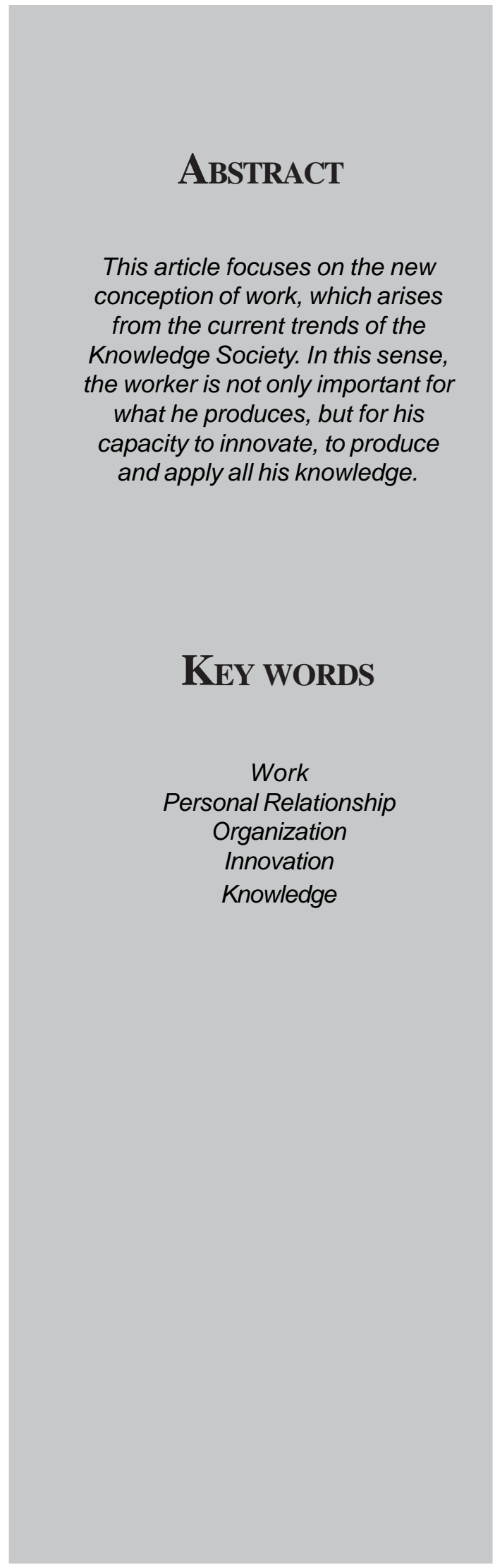


El trabajo no cualificado y sustituible sin coste es una excepción. El coste de sustitución de determinados trabajos es muy elevado. $Y$ no se trata de un coste que se compense con una inversión adicional de capital. No se trata sólo de llevar un cuidadoso proceso de selección y financiar algún curso de formación. Se trata de que la nueva persona necesitará tiempo. Crear relaciones de confianza, desarrollar redes o adquirir conocimientos específicos del puesto requieren tiempo. Y durante este tiempo habrá un coste de oportunidad que afectará no sólo al puesto en cuestión sino que puede afectar en red y en cadena a otros muchos puestos, que no alcanzarán su rendimiento óptimo.

\section{El trabajador del conocimiento y la innovación}

El trabajador del conocimiento no se define por su coste, ni por su productividad. Se define por su capacidad de innovación: capacidad de elaborar conocimiento y aplicarlo. La formación a medida y preferiblemente autogestionada y el desarrollo de las capacidades personales se convierten en elementos clave, así como el desarrollo de redes y el trabajo en equipo.

Drucker explica de forma muy ilustrativa por qué la eficiencia en la producción tiene un límite como motor de desarrollo económico: Cuando Taylor empezó -explica-, nueve de cada diez trabajadores realizaban un trabajo manual, haciendo o trasladando cosas en fábricas, agricultura, minería o transporte. Hacia 1990, habían quedado reducidas a un quinto de la fuerza laboral en los países desarrollados; hacia 2010, no serán más de una décima parte. Aumentar la productividad de los obreros manuales en fábricas, agricultura, minería o transporte ya no es un hecho que pueda crear riqueza por sí mismo (en EEUU sigue subiendo al ritmo histórico de 3,5\% - 4\%). A partir de ahora, lo que importa es la productividad de los trabajadores no manuales (Drucker, 2003: 40). El trabajo cerebral no puede ser medido según las pautas vigentes para el trabajo manual. El trabajador del conocimiento no produce nada que sea efectivo en sí mismo. Produce conocimientos, ideas, información. El mayor saber, si no es aplicado a la acción o la conducta, es un conjunto de datos sin sentido (Drucker, 2003: 87-88).

Según Daniel Goleman el 77\% de los estadounidenses son trabajadores del conocimiento, que define como personas cuyo trabajo no depende de lo que les diga alguien sino de sí mismos (Goleman, 1999: 427). Paralelamente a que las personas dependen más de sus propios impulsos que de órdenes que les dicten otros, dependen cada vez más del trabajo en redes y en equipo. Esto, puede parecer paradójico, pero no lo es: por un lado, las personas elaboran conocimiento sobre la base de otros conocimientos, y además, la utilidad o traducción en resultado económico de este conocimiento depende de que se haga llegar a quien lo pueda convertir en factor productivo.

Goleman cita un ejemplo ilustrativo de la relevancia que viene adquiriendo la transmisión del conocimiento: Robert Kelley, de la Universidad Carnegie-Mellon, lleva muchos años formulando a las personas que trabajan en una amplia variedad de empresas la misma pregunta: '¿Qué porcentaje del conocimiento que precisa para llevar a cabo su trabajo está contenido en su propia mente?'. En 1986 la respuesta giraba aproximadamente en torno al $75 \%$, pero en 1997 el porcentaje había descendido ya a una cifra situada entre el 15 y el 20\% (Goleman, 1999: 278). Los trabaja-dores del conocimiento ejercen su trabajo tomando decisiones, con un amplio grado de libertad y compartiendo con otros el conoci-miento que elaboran. 
Management, trabajo y capital

La clasificación dual de los factores económicos en trabajo y capital hoy no sirve para explicar la realidad económica. Pensadores como Drucker nos han ayudado a identificar otro factor, que hoy se define sin duda como el más determinante de los tres: el management (gerencia-dirección-gestión-administración). Este autor explica que el management es hoy la 'aplicación del saber al saber' (Drucker, 2003: 40), como paso siguiente a la 'aplicación del saber al trabajo', que tuvo como resultado un siglo de boom productivo (Drucker, 2003: 39). Al tiempo que la función del gerente se ha transformado, la manera en que las per-sonas de una organización deben relacionarse entre sí y con el gerente ha sufrido una transformación paralela. Recuerda Drucker que no hace tanto un gerente era definido como 'alguien que es responsable del trabajo de unos subordinados'; era un 'jefe' y gestión era jerarquía y poder. A principios de los cincuenta la definición había cambiado a 'un gerente es responsable del rendimiento de la gente'. Ahora sabemos que la anterior es también una definición demasiado estrecha: 'un gerente es responsable de la aplicación y el rendimiento del saber' (Drucker, 2003: 45)

El trabajador del conocimiento está a dos aguas entre el management y el trabajo. La delimitación entre los tres factores no tiene fronteras nítidas. Capital y dirección en origen eran uno, eran indisociables. El empresario adinerado era inversor y patrón a la vez. El management se está desplazando del capital, donde tuvo su origen, al trabajo, con el que en cierta medida se está fusionando. Y este nuevo escenario esconde detrás el cambio profundo al que hacía mención.

\section{La dirección descentralizada en la nueva organización}

En la actualidad, la técnica de dirección autoritaria, planificadora y centralizada se observa cada vez menos adecuada para las organizaciones, que necesitan cuestionarse continuamente cómo pueden mejorar y aprovechar oportunidades. Estas oportunidades se presentan muchas veces en las capas bajas de la empresa. Descubrirlas requiere que la persona no se limite únicamente a realizar su tarea, sino que esté comprometida con las metas de la empresa. La transparencia desde la cúpula directiva y un enfoque compartido hacia el rendimiento son factores clave.

Reinhard Mohn -fundador de la Fundación Bertelsmann- expone que la creciente complejidad de las tareas económicas exige la descentralización de las decisiones. Hoy, las estructuras jerárquicas ya no pueden proporcionar el sinnúmero de impulsos de mando necesarios. Por eso, hemos aprendido a repartir la responsabilidad entre muchas personas y a actuar autónomamente hasta en los niveles inferiores. Este cambio en la praxis directiva impone una actitud frente a la empresa que se basa en la identificación surgida de la convicción. La praxis de la dirección tradicional, que se deriva del derecho a propiedad y se apoya en la disciplina jerárquica, queda claramente relegada. (Mohn, 2004: 62,67)

La técnica de dirección cooperativa permite aprovechar la potencialidad y diversidad de muchas personas y descender la toma de decisión al nivel más adecuado. Se presenta mucho más eficaz y relega rotundamente al estilo tradicional, que gira sobre la hipótesis de que el conocimiento se concentra en la alta dirección. Cuando en realidad en toda organización competitiva, al menos, en toda que integre a trabajadores del conocimiento, el conocimiento está absolutamente disperso en todas y cada una de las mentes. 


\section{Cultura cooperativa frente a cultura de la confrontación}

Los discursos y lenguaje empleados dentro de la cultura de la confrontación no son acordes a los nuevos tiempos y a la nueva realidad del trabajo.

'La economía de suma cero no funciona. La economía funciona si todos ganan. Si yo no gano junto con los accionistas, los clientes, etc. va mal'. Lo decía Santiago García Echevarría en la última conferencia que pronunció en la Universidad de Deusto (Donostia, Diciembre 2005). Economía de suma cero es pensar en que 'el pastel es fijo y se trata de conseguir la mayor porción para nosotros'. Si miramos hacia dentro de la empresa desde esta perspectiva, se enquistan los problemas en torno a la posición de los distintos grupos de interés. Si nos referimos hacia fuera, intentaremos hacernos valer de nuestro poder de negociación con respecto a clientes o proveedores para mejorar nuestros márgenes. Son todos ellos caminos de corto recorrido, que se enmarcan dentro de la cultura de la confrontación. Yo gano si tú pierdes.

Ahora sabemos que lo que en realidad nos sirve para avanzar es la cooperación, la transparencia y la constante innovación. Y este enfoque sirve tanto hacia dentro de la empresa, como hacia fuera. Es la manera de que todos ganemos.

Es condición de la cultura de la cooperación algo tan ingenuo -y difícil de asimilar dentro de la cultura de la confrontación- como presumir buena fe en la parte 'contraria' o 'cooperante'. Si no hay presunción de buena fe, la cooperación es inviable. Deberíamos descender a niveles de cooperación donde podamos presumir buena fe e ir construyendo la confianza. La confianza es el elemento básico de la cooperación. Esto hace que donde hay cooperación se hable de Capital Social.
Hará falta tiempo para ir asimilando estos cambios, pero algo claro es que la cultura de la confrontación no sirve en este contexto.

\section{Los agentes sociales: ¿un nuevo rol?}

Los agentes sociales quizá deberían buscar un nuevo espacio donde puedan aportar en este escenario donde la cultura de la confrontación se presenta inválida.

Mohn explica así cuál fue el origen de los agentes sociales: En el pasado el clima laboral en las empresas se caracterizaba por una estricta disciplina y unas obligaciones de gran dureza. Los intereses de los trabajadores no iban más allá de asegurarse el sustento. La consideración social sólo dependía de la actitud individual de algunos empresarios y todavía no era un asunto público. Más tarde, con la rápida expansión de la industria, esta forma de capitalismo liberal condujo a problemas y enfrentamientos sociales que desencadenaron una intervención del poder estatal.

Al principio el poder político participó en esta tarea dirigiendo; pero como se trataba de un asunto ajeno a él, tiempo después tomó la decisión de delegar la responsabilidad de elaborar las reglas de la vida laboral en los sindicatos y en las asociaciones de empresarios. Así el modo en que surgieron los agentes sociales explica que se use el concepto de 'cultura de la confrontación', que procede de la praxis de la dirección política (Mohn, 2004: 57).

Competir en la sociedad del cambio, intentar constituir de la innovación nuestra ventaja competitiva, exige flexibilidad. Flexibilidad que convive muy bien con la confianza y la cooperación, mientras que la confrontación y la desconfianza exigen regulación. 
¿Pueden extender los sindicatos su rol en la sociedad? ¿Pueden contribuir a facilitar la identificación de metas entre persona y organización? ¿Pueden superar el discurso de la confrontación y enfocarse hacia aspectos más acordes con la cultura de la cooperación? Les invito a que reflexionen. En mi opinión hay un gran campo de acción: intentar promover que el trabajo se vaya convirtiendo cada vez más en espacio de desarrollo personal o que se den las condiciones adecuadas para que se aproveche la potencialidad de todas las personas.

Desde el ámbito empresarial y también en aras a reducir la confrontación es importante interiorizar y exteriorizar que la meta de una organización va más allá de la obtención del beneficio. Sin beneficio la mayor parte de las organizaciones empresariales son inviables. No obstante, una vez cubierto el mínimo que le garantiza la inversión, la obtención del beneficio es un objetivo más de la organización. No es el único.

\section{La responsabilidad del cambio}

Los directivos y responsables de dirigir las organizaciones de todo tipo que actúan en la vida económica son los que deben jugar un papel principal en propiciar el cambio de concepción del trabajo en el sentido descrito en estas líneas. Deben fomentar en sus organizaciones estilos, dinámicas y formas de trabajo que impulsen la creatividad, la libertad, la cooperación, el aprendizaje, la inteligencia.
O dicho de otro modo, que aprovechen la diversidad y potencialidad de sus personas para convertirse en organizaciones que basan su ventaja competitiva en la innovación. Muchas organizaciones innovadoras contagiarán al resto y nos arrastrarán a dar el salto al estadio de la innovación.

Seguir creando empleo y riqueza a pesar de realidades como la deslocalización y la emergencia de economías altamente competitivas, exige orientarnos hacia nuevos factores que nos hagan competitivos.

Termino citando a Alfonso Vázquez que en su libro 'La imaginación estratégica' habla de la paradoja de esta nueva era, donde a la vez que se crean hoy oportunidades inimaginables ayer, se desmoronan colosos cuya salud -capacidad para competir- no se ponía en cuestión. 'No olvidemos que la innovación, la creatividad con su enorme impulso transformador, tienen también características destructivas. Todo aquello que no puede adaptarse al ritmo que imprime y que no queda suficientemente protegido por poderes extraños al mundo de la competitividad resulta barrido, más pronto que tarde' (Vázquez, 2000: 167).

Algunos tienen mayor responsabilidad en propiciar las condiciones adecuadas para que se aprovechen las oportunidades, que surjan tanto dentro de las organizaciones, como en la relación entre organizaciones. No obstante, se trata de un cambio cultural de tal calado que todos los que intervenimos en la sociedad, con nuestro mayor o menor papel, deberemos ir favoreciendo. 


\section{Bibliografía}

DRUCKER, Peter (2003): 'Drucker esencial', Edhasa, Barcelona.

GOLEMAN, Daniel (1999): 'La práctica de la inteligencia emocional', Ed. Kairós, Barcelona.

MOHN, Reinhard (2004): ‘La responsabilidad social del empresario', Círculo de Lectores, Barcelona.

VÁZQUEZ, Alfonso (2000): ‘La imaginación estratégica’, Ed. Granica, Barcelona. 
